OPEN ACCESS

Edited by:

Caroline Remond,

Université de Reims

Champagne-Ardenne, France

Reviewed by:

Antti llmari Koponen,

VTT Technical Research Centre of

Finland Ltd., Finland

Rupinder Singh,

Guru Nanak Dev Engineering

College, India

*Correspondence:

Marie-Joo Le Guen

mariejoo.leguen@scionresearch.com

Specialty section:

This article was submitted to Chemical and Process Engineering,

a section of the journal

Frontiers in Chemistry

Received: 15 June 2019 Accepted: 14 October 2019

Published: 31 October 2019

Citation:

Le Guen M-J, Hill S, Smith D,

Theobald B, Gaugler E, Barakat $A$ and

Mayer-Laigle C (2019) Influence of

Rice Husk and Wood Biomass

Properties on the Manufacture of

Filaments for Fused Deposition

Modeling. Front. Chem. 7:735.

doi: 10.3389/fchem.2019.00735

\section{Influence of Rice Husk and Wood Biomass Properties on the Manufacture of Filaments for Fused Deposition Modeling}

\author{
Marie-Joo Le Guen 1*, Stefan Hill ', Dawn Smith ${ }^{1}$, Beatrix Theobald ${ }^{1}$, Evamaria Gaugler', \\ Abdellatif Barakat ${ }^{2}$ and Claire Mayer-Laigle ${ }^{2}$
}

${ }^{1}$ Scion, Rotorua, New Zealand, ${ }^{2}$ IATE, Univ Montpellier, CIRAD, INRA, Montpellier SupAgro, Montpellier, France

Additive manufacturing or 3D printing has the potential to displace some of the current manufacturing techniques and is particularly attractive if local renewable waste resources can be used. In this study, rice husk, and wood powders were compounded in polylactic acid (PLA) by twin screw extrusion to produce filaments for fused-deposition modeling 3D printing. The biomasses were characterized in terms of physical features (e.g., particle size, density) and chemical compositions (e.g., solid state nuclear magnetic resonance, ash content). The two biomasses were found to have a different impact on the rheological behavior of the compounds and the extrusion process overall stability. When comparing the complex viscosity of neat PLA to the biomass/PLA compounds, the integration of wood powder increased the complex viscosity of the compound, whereas the integration of rice husk powder decreased it. This significant difference in rheological behavior was attributed to the higher specific surface area (and chemical reactivity) of the rice husk particles and the presence of silica in rice husks compared to the wood powder. Color variations were also observed. Despite the biomass filler and rheological behavior differences, the mechanical properties of the 3D printed samples were similar and predominantly affected by the printing direction.

Keywords: 3D printing, rice husk, wood, biomass, composites, extrusion

\section{INTRODUCTION}

The popularity of incorporating lignocellulosic biomasses in thermoplastic polymers has increased significantly due to their sustainability advantage, low density, thermal, and noise insulation capacity and stiffening performances (Le Guen and Newman, 2007; Müssig, 2010; Gallos et al., 2017; Lammi et al., 2018). The properties of the composites are related to (a) the amount of biomass incorporated and (b) the interactions between the polymeric matrix and the lignocellulosic particles in terms of physical (e.g., surface area, aspect ratio) and chemical interactions (e.g., interface compatibilisation). Amongst the lignocellulosic feedstocks available, rice husk is of particular interest due to its current abundancy (i.e., estimated between 128 and 148 million tons of unutilized waste) (Giddel and Jivan, 2007; Pode, 2016), and chemical make-up. It is composed of around $80-85$ wt.\% lignocellulosic materials (e.g., cellulose, hemicellulose, lignin), 15-20 wt.\% of amorphous silica and 1.1 to 2.5 wt.\% of proteins (Juliano et al., 1987; Vadiveloo et al., 2009; Ummah et al., 2015). 
Previous research studies have reported its potential applications in composite structures (Kumar et al., 2012), as an energy feedstock (Chungsangunsit, 2009) or amorphous silica feedstock (Yalçin and Sevinç, 2001). In parallel, the incorporation of nanosilica in polylactic acid (PLA) was also reported to improve the thermal stability and mechanical properties of composites ( $\mathrm{LV}$ et al., 2016).

$3 \mathrm{D}$ printing $(3 \mathrm{DP})$ or additive manufacturing is an emerging technology that enables the creation of innovative designs and the combination of materials that were previously impossible or impractical to make. The incorporation of fillers in 3DP has demonstrated that the filler's physical features could be transferred to the 3D printed object (Montalvo Navarrete et al., 2018; Zeidler et al., 2018). These attractive traits have been demonstrated with wood (Mirko et al., 2016; Tao et al., 2017), clays (Revelo and Colorado, 2018), metals (Gibson et al., 2018), and seashells (Graichen et al., 2017; Singamneni et al., 2018a; Zeidler et al., 2018).

The combination of (a) the inherent properties of polymerfilled compounds and (b) the control of the 3D printing process directionality, leads to new functionalities to printed objects (Liles et al., 2018; Wang et al., 2018). Examples of such functionalities for lignocellulosic feedstocks include hydromorphic properties (Le Duigou et al., 2016; Sydney Gladman et al., 2016), electrical conductivity (Shao et al., 2018) and vibration damping (Zeidler et al., 2018).

In this present research, the influence of rice husk powder integrated into a PLA matrix is investigated for fused deposition modeling (FDM) 3DP applications, and compared to wood flour PLA 3D prints. The impact of the two biomasses during the extrusion compounding process, and on the mechanical properties of $3 \mathrm{D}$ printed rectangular parallelepipeds are observed and quantified.

\section{MATERIALS AND METHODS}

\section{Biomasses and Polymer}

Carmargue rice (Oryza) husks were supplied from Silo des Tourelles- Comptoir Agricole du Languedoc (Aigues Mortes, France). The husks were first sieved with a screen of $0.8 \mathrm{~mm}$ using a vibratory sieve shaker 400 (Ritec, France) to remove soil dust and stones. The husks were subsequently milled in a vibratory ball mill model DM-1 (Sweco ${ }^{\circledR}$, USA) consisting of a $36 \mathrm{~L}$ abrasion-resistant elastomer grinding chamber filled with $25 \mathrm{~kg}$ of ceramics cylinders (diameter and length of $13.5 \mathrm{~mm}$ ) and $25 \mathrm{~kg}$ of ceramics balls (diameter of $13.5 \mathrm{~mm}$ ). The chamber's motion was controlled by a vibrating mechanism composed of high-tensile steel springs. One kilogram of rice husk was placed in the chamber and milled for $10 \mathrm{~h}$ to obtain fine rice husk powder. The ground powder was dried in an oven at $60^{\circ} \mathrm{C}$ for $12 \mathrm{~h}$ and stored in aluminum foil vacuum packaging bags prior to utilization.

Wood flour (Pinus radiata D. Don) was supplied by a plywood mill (Carter Holt Harvey, Kinleith Mill, Tokoroa, New Zealand). Only the particles below $125 \mu \mathrm{m}$ were used after separation using a 43305 F motorized sieve shaker (Humboldt, USA) and $125 \mu \mathrm{m}$ mesh sieve (Endercotts, UK). The wood flour powder was dried at $100^{\circ} \mathrm{C}$ for at least $24 \mathrm{~h}$ prior to extrusion.

PLA 3001D was obtained from Nature works (USA) and dried overnight prior to extrusion. The PLA and PLA compounds were dried for at least $4 \mathrm{~h}$ at $55^{\circ} \mathrm{C}$ prior to extrusion.

\section{Processing \\ Compounding}

The filaments were made in two sequential steps: (a) compounding the polymer and biomasses at 10 wt.\% into pellets and (b) extrusion of the filament for FDM. Both steps were carried out on a $26-\mathrm{mm}$ scientific twin screw, co-rotating extruder LTE26-40 (Labtech Engineering Ltd, Thailand), which had a $40 \mathrm{~L} / \mathrm{D}$ ratio and was fitted with a vacuum crammer. During Step (a), materials were hand-mixed in plastic bags and fed into the volumetric feeder. The speed of the feeder was set to $20 \mathrm{rpm}$. The extruder screw speed was set to $200 \mathrm{rpm}$. The temperature was set to $190^{\circ} \mathrm{C}$ at the first 5 zones and $200^{\circ} \mathrm{C}$ at the last 5 zones. Pellets were cut to around $2 \mathrm{~mm}$ in length. During Step (b), the settings of the twin-screw extruder were modified (Table 1) and the pelletizer replaced by a winding unit set to produce a $1.75 \mathrm{~mm}$ diameter filament.

\section{D Printing}

The objects were printed on a M2 fused deposition modeling printer (Makergear, USA) fitted with a $0.75 \mathrm{~mm}$ die nozzle. The platform temperature was set at $70^{\circ} \mathrm{C}$ and the nozzle temperature at $210^{\circ} \mathrm{C}$. Rectangular beams $(60 \times 10 \times 2.5 \mathrm{~mm})$ for flexural testing were printed using slicing software (Simplify $3 \mathrm{D}^{\circledR}$, USA) based on $0.2 \mathrm{~mm}$ layers thickness and no strand overlap. The $3 \mathrm{D}$ printing direction was carried out at either $0^{\circ}$ or $90^{\circ}$ of the beam length.

\section{Characterization of the Biomasses Physical Characterization \\ Particle size distribution}

The particle size distribution of the risk husk powder and wood flour powder were measured by a laser diffraction particle size analyzer Hydro 2000S (Malvern Instruments Ltd., UK) with distilled water/ethylic alcohol solution (50:50 in volume) to allow good powder dispersion whilst avoiding swelling. The results are expressed using the Mie method with a refraction index of 1.53 corresponding to those of sawdust particles (Malvern, 2007). The results are generated in volume, based on the assumption that the particles are spherical. Five replicates were carried out for each biomass and the mean average distribution is reported.

TABLE 1 | Extrusion settings for Step (b) to manufacture the FDM filaments.

Temperature $\left({ }^{\circ} \mathrm{C}\right)$ $160,170,170,170,180,180,190,190,200,200$

Screw speed (rpm) 200

Feed speed (rpm) 8

Speed of haul-off unit (rpm) 


\section{Scanning electron microscopy (SEM)}

Rice husk and wood powders were imaged with a scanning electron microscope Phenom Pro-X (Phenom, France) using a charge reduction sample holder and an acceleration voltage of 5 $\mathrm{kV}$ (wood powder) and $10 \mathrm{kV}$ (rice husk powder), respectively.

\section{Tapped density and apparent density}

The apparent and tapped density was measured in duplicate using a standard tapped density analyzer (Autotap, Quantachrome instrument ${ }^{\circledR}$, USA). The experiment consisted of filling a graduated test tube with $200 \mathrm{~mL}$ of powder and submitting it to 1,500 taps. The apparent and tapped densities were calculated as the ratio of the mass of the powder to the initial and final volume respectively.

\section{Chemical Characterization pH measurements}

One gram of biomass powder was stirred into $15 \mathrm{~mL}$ of distilled water at room temperature. Four $\mathrm{pH}$ measurements over $4 \mathrm{~h}$ were recorded using a ph meter (Mettler Toledo, USA). The four measurements were then averaged.

\section{Solid-state nuclear magnetic resonance (NMR) spectroscopy}

Solid state CP-MAS (Cross Polarization-Magic Angle Spinning)

${ }^{13} \mathrm{C}$ Nuclear Magnetic Resonance spectra were acquired at 50.3 $\mathrm{MHz}$ on a Bruker Avance III 200 spectrometer (Bruker BioSpin, Germany) fitted with a $4 \mathrm{~mm}$ solid state MAS probe (Bruker BioSpin, Switzerland). The samples were packed into a $4 \mathrm{~mm}$ rotor and spun at $5 \mathrm{kHz}$. Each $3 \mu \mathrm{s}$, a $90^{\circ}$ proton preparation pulse was followed by a $1 \mathrm{~ms}$ contact time and a $30 \mathrm{~ms}$ acquisition time, with proton decoupling, and a $1.5 \mathrm{~s}$ recycle delay. All spectra were calibrated so that the cellulose I $\beta$ interior $\mathrm{C} 4$ peak was assigned a value of $89.3 \mathrm{ppm}$ relative to tetramethylsilane (Newman et al., 1993).

\section{Ash content}

Around $2 \mathrm{~g}$ of powder was first dried in an oven at $130^{\circ} \mathrm{C}$ during $90 \mathrm{~min}$ and weighed to determine the dry mass $\left(\mathrm{m}_{\mathrm{s}}\right)$. The sample was subsequently heated at $900^{\circ} \mathrm{C}$ for $2 \mathrm{~h}$ and re-weighted $\left(\mathrm{m}_{\mathrm{r}}\right)$ after cooling in a desiccator to room temperature. The ash content was calculated according to:

$$
\text { Ash }=100 \cdot \mathrm{m}_{\mathrm{r}} / \mathrm{m}_{\mathrm{s}}
$$

Where:

Ash is in percentage,

$\mathrm{m}_{\mathrm{s}}$ is the sample dry mass in grams,

$\mathrm{m}_{\mathrm{r}}$ is the sample residual mass in grams.

Experiments were carried out in triplicate and averaged.

\section{Chemical composition}

Carbohydrates and lignin content of the biomasses were measured after concentrated acid hydrolysis. The lignin content in samples was determined by the Klason method. Briefly, $100 \mathrm{mg}$ of dried samples were treated with $72 \% \mathrm{v} / \mathrm{v} \mathrm{H}_{2} \mathrm{SO}_{4}$ at ambient temperature for $2 \mathrm{~h}$. The solutions were diluted with water to $12 \% \mathrm{v} / \mathrm{v} \mathrm{H}_{2} \mathrm{SO}_{4}$ and autoclaved at $100^{\circ} \mathrm{C}$ for $3 \mathrm{~h}$. The hydrolysates were filtered $(10 \mu \mathrm{m})$ and the Klason lignin content was determined as the weight of the residue after drying at $105^{\circ} \mathrm{C}$ for $24 \mathrm{~h}$. The monomeric sugars glucose, xylose, and arabinose were determined using high-pressure liquid chromatography (HPLC). A Waters system, using a BioRad HPX-87H column at $40^{\circ} \mathrm{C}$ and $0.3 \mathrm{~mL} / \mathrm{min}$ was used for analysis. All analyses were performed in triplicate.

\section{Characterization of the Biomass Compounds \\ Rheology}

Complex viscosity of the neat PLA and the compounds was measured on a AR 2000 rheometer (TA instruments, USA). The experiments were recorded in triplicate in frequency sweeps from 100 to $1 \mathrm{~Hz}$ at $200^{\circ} \mathrm{C}$ and $1 \%$ strain. The linear visco-elastic region was determined at $1 \mathrm{~Hz}$.

\section{Molecular Weight}

Gel Permeation Chromatography (GPC) experiments were carried out on a using a styrene divinylbenzene (SDVB) copolymer gel column set consisting of 2 analytical columns (SDV Lux Lin M; $5 \mu \mathrm{m} ; 300 \times 8 \mathrm{~mm}$; PSS Polymer Standards Service $\mathrm{GmbH}$, Germany) and a precolumn (SDV analytical precolumn, $5 \mu \mathrm{m} ; 50 \times 8 \mathrm{~mm}$; PSS Polymer Standards Service $\mathrm{GmbH}$, Germany). The flow rate was set to $1 \mathrm{~mL} / \mathrm{min}$, the system was conditioned to $30^{\circ} \mathrm{C}$ and an injection volume of 100 $\mu \mathrm{L}$ was used. Samples were prepared in triplicate by dissolving 6 to $8 \mathrm{mg}$ of sample in chloroform to a concentration of 2.0 $\mathrm{mg} / \mathrm{mL}$ overnight. The solutions were filtered through a $0.45 \mu \mathrm{m}$ PTFE filter. The instrument (Knauer, Germany) was calibrated using 12 polystyrene standards (ReadyCal Polystyrene standards; PSS Polymer Standards Service GmbH, Germany) ranging from 370 to $2,520,000 \mathrm{~g} / \mathrm{mol}$. A conventional calibration curve was established by measuring the elution volume of the standards and plotting it against the logarithm of the molar mass. The calibration data was fitted with a fourth order polynomial function $\left(r^{2}=1.00\right)$. Number average molecular weight $(\mathrm{Mn})$, weight average molecular weight $(\mathrm{Mw})$ and polydispersity index (PDI) were calculated from the detector response using the WinGPC UniChrom software (PSS Polymer Standards Service $\mathrm{GmbH}$, Germany).

\section{Dynamic and Quasi-Static Mechanical Test}

Specimens for dynamic mechanical thermal analysis (DMTA) and mechanical analysis in flexural mode were tested in 3-point bending mode on a RSA-G2 DMTA (TA instruments, USA) using a $40-\mathrm{mm}$ span. Specimens were conditioned for $48 \mathrm{~h}$ at $23^{\circ} \mathrm{C}$ $\left( \pm 2^{\circ} \mathrm{C}\right)$ and $50 \%( \pm 5 \%)$ relative humidity.

Dynamic testing was carried out from 23 to $80^{\circ} \mathrm{C}$ at a rate of $5^{\circ} \mathrm{C} / \mathrm{min}$. Strain oscillations of $0.1 \%$ at a frequency of at $1 \mathrm{~Hz}$ were applied. The storage modulus (E') and $\tan \delta$ were recorded throughout the test. Each formulation and printing direction was tested in triplicates.

Flexural testing was carried out on an Instron 5566 universal testing machine (Instron, USA) fitted with a $10 \mathrm{kN}$ load cell at a rate of $2 \mathrm{~mm} / \mathrm{min}$. Flexural modulus, strength and strain were recorded throughout the test. At least 5 samples for each formulation were tested. 


\section{RESULTS}

\section{Characterization of the Biomass Particles}

The wood powder particles were larger than those of the rice husks with a median size of $209.9 \mu \mathrm{m}$ for the wood powder and $28.1 \mu \mathrm{m}$ for rice husk powder (Table 2). Both powders exhibit a widespread distribution with a similar SPAN around 3.3. SPAN expresses the width of the distribution (D90D10/D50). Rice husk powder contains a considerable proportion of fine particles below $20 \mu \mathrm{m}$ whereas wood powder has a high content of coarse particle (above $400 \mu \mathrm{m}$ ) as observed in the shape of the particle size distribution graph (Figure 1). As a result, the specific surface area calculated from the particle size distribution is approximately 9 times higher for rice husk powder than for wood powder. However, the particle size distributions must be interpreted with caution as laser diffraction model calculations assume spherical homogeneous particles (Bohren and Huffman, 1983).

When looking at the biomass micro-morphology by SEM, large fibrous structures, $>125 \mu \mathrm{m}$ in length, are visible in the wood flour in contrast with low aspect ratio particles of the rice husk particles which supports the laser diffraction measurements (Figure 2). The presence of such particle sizes despite the sieving step is explained by their high aspect

TABLE 2 | Physical characterization of the wood and rice husk powders including particle size distribution indicators, specific surface area and densities (D10: 10th percentile, D50: Median Size, D90: 90th percentile).

\begin{tabular}{lcc}
\hline & Wood powder & Rice husk powder \\
\hline D10 $(\mu \mathrm{m})$ & 48.4 & 3.5 \\
D50 $(\mu \mathrm{m})$ & 209.9 & 28.1 \\
D90 $(\mu \mathrm{m})$ & 748.1 & 95.2 \\
Specific surface area & 0.074 & 0.65 \\
SPAN $((\mathrm{d} 90-\mathrm{d} 10) / \mathrm{d} 50)$ & 3.26 & 3.33 \\
Apparent density & 8.2 & 45.2 \\
$\left(\times 10^{-2} \mathrm{~kg} \cdot \mathrm{L}^{-1}\right)$ & & 56.9 \\
Tapped density & 10.0 & \\
$\left(\times 10^{-2} \mathrm{~kg} \cdot \mathrm{L}^{-1}\right)$ & &
\end{tabular}

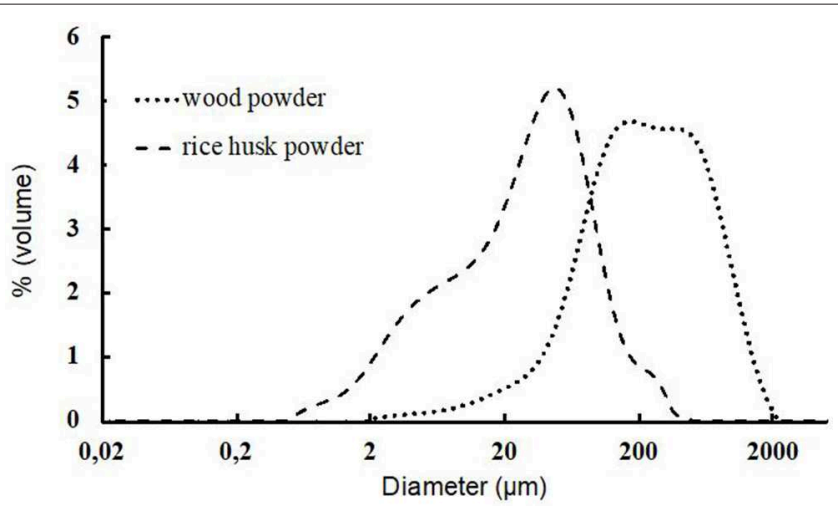

FIGURE 1 | Particle size distribution for the wood powder (dotted line) and rice husk powder (dashed line). ratio that allowed them to pass through the mesh. The size and morphological differences contribute to explain the lower apparent density of the wood biomass through a lesser packing efficiency.

In terms of chemical compositions determined by HPLC, the two biomasses are consistent with literature for lignocellulosic feedstocks (Table 3) (Müssig, 2010). The main differences between powders are (a) higher lignin content for the wood powder and (b) higher ash content for the rice husk powder (i.e., 15.7 wt.\% compared to 0.16 wt. $\%$ for wood). The higher ash content in rice husks is explained by the presence of silica and contributes to the five-fold difference recorded in tapped density (Table 3) (Hamdan et al., 1997). The lack of a $100 \%$ mass balance was attributed to the presence of water soluble extractives. Those were found to be present in higher quantities in wood powder than in rice husk powder.

The chemical compositions of the powders as determined by ${ }^{13} \mathrm{C}$ solid-state NMR were consistent with lignocellulosic biomass. The major peaks observed in the wood powder were attributed to cellulose (C1-C6), lignin methoxyl (56 ppm) and aromatic/phenolic groups, with minor contributions from hemicelluloses (Figure 3A) (Gil and Neto, 1999). The rice husk powder showed similar signals with the addition of peaks attributed to amide carbonyls $(\sim 175 \mathrm{ppm})$ and signals predominantly from the $\mathrm{C}_{\beta} / \mathrm{C}_{\gamma}$ amino acid side chains $\left(\mathrm{C}_{\gamma}\right.$ 15-25 ppm and $C_{\beta}$ 25-35 ppm) overlapping with signals from acetylated hemicelluloses (Figure 3B) (Bruker BioSpin, 2018). The amino acid signals were attributed to the known protein content present in rice husk (Juliano et al., 1987; Vadiveloo et al., 2009).

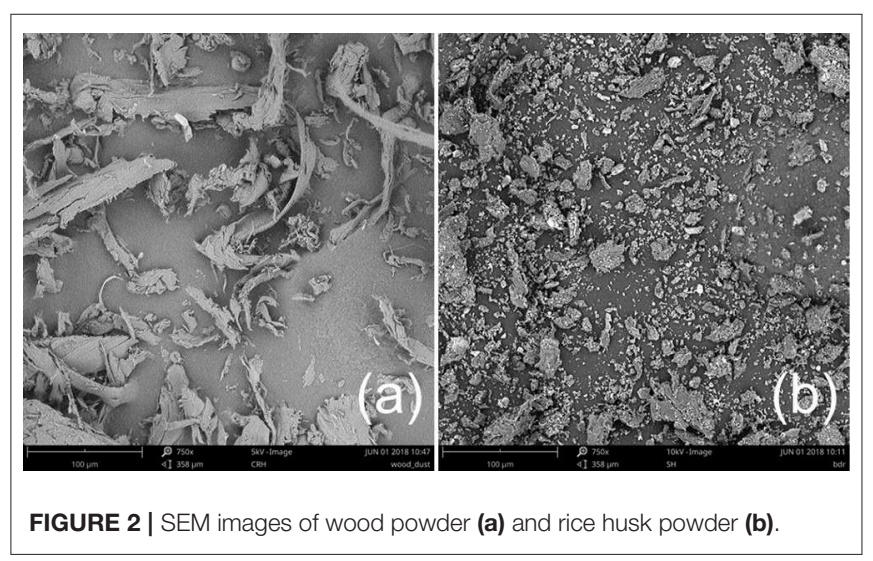

TABLE 3 | Chemical composition in mass percentage of the biomass.

\begin{tabular}{lcc}
\hline & Wood powder & Rice husk powder \\
\hline Hemicellulose & $17.1 \pm 0.8$ & $21.8 \pm 0.7$ \\
Cellulose & $44.3 \pm 1.0$ & $40.6 \pm 1.0$ \\
Lignin & $28.0 \pm 0.8$ & $19.4 \pm 1.5$ \\
Ash (minerals) & $0.16 \pm 0.1$ & $15.7 \pm 0.7$ \\
Total & $89.6 \pm 2.7$ & $97.5 \pm 3.9$
\end{tabular}




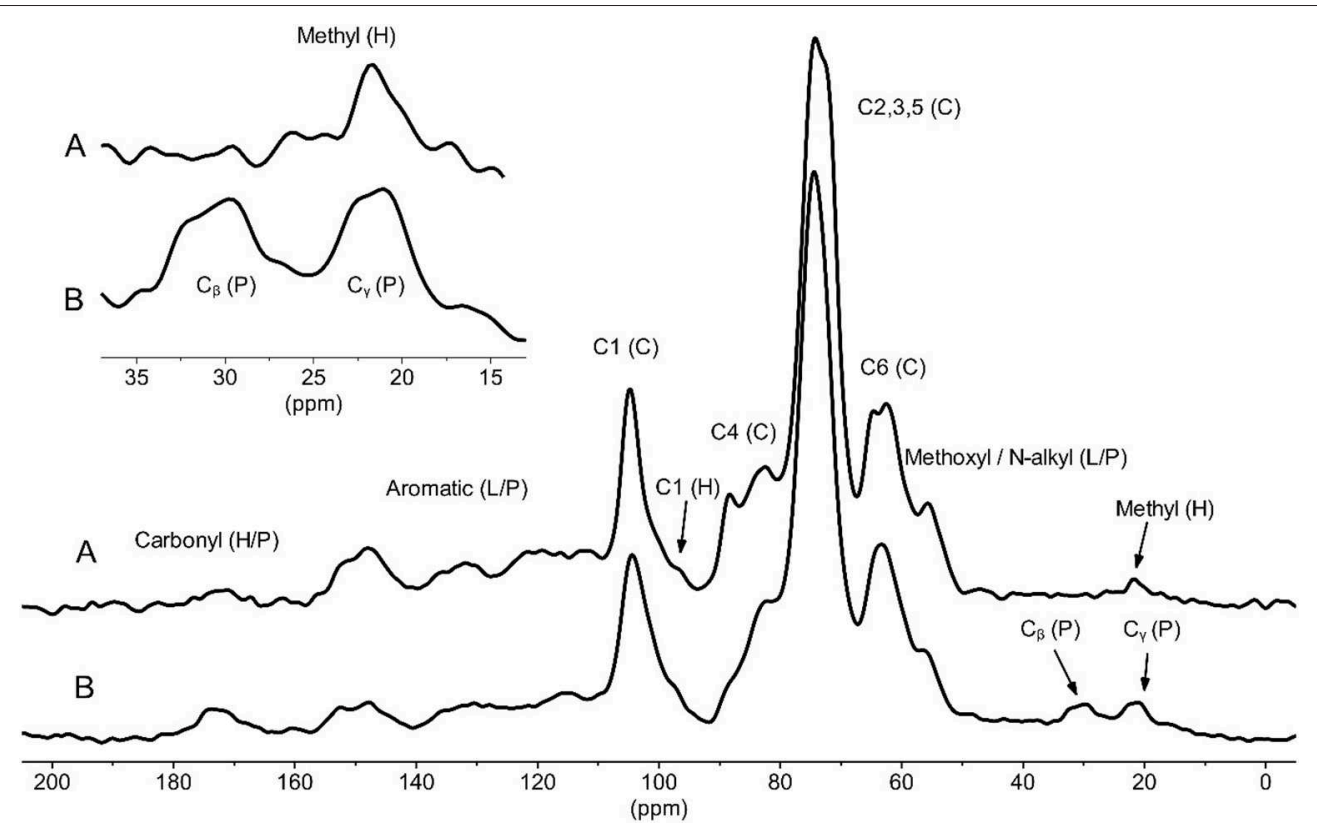

FIGURE 3 | Solid-state NMR of the wood powder (A) and rice husk powder (B). P, protein; H, hemicelluloses; L, lignin; C, cellulose. Top left spectrum is a zoom in of the $10-40$ ppm range.

\section{Extrusion Process Stability}

During the compounding step, the die pressure was significantly different between the wood and the rice husk powders. It ranged from 68 to 73 bars and 22 to 24 bars for the wood and rice husk compounds, respectively. Low die pressure, substantial die surge and color change were observed during rice husk compounding. The processing differences were initially attributed to the particle variation in apparent densities and sizes, however, it did not account for the variation in colors. It is known that compounding lignocellulose biomass in polymer can oxidize the carbohydrates contained in the biomass and lead to a darkening of the compounds depending on the processing conditions (i.e., high shear, high temperature) (Muniyasamy, 2013; Gallos et al., 2017). Yet the variation in color between the raw feedstocks and the compounds was more intense for the PLA rice compound than those of the PLA wood, and accentuated in the FDM filament (Figure 4). Ball milling of lignocellulosic biomass during an extended period (i.e., $>120 \mathrm{~min}$ ) is known to increase surface area, decrease cellulose crystallinity and decrease the carbohydrate's degree of polymerization that consequently increases the particle surface reactivity (Vaidya et al., 2016; Gao et al., 2017). This reactivity could explain the difference of coloration caused by chemical reactions triggered by the rice husk compared to the wood powder.

During the FDM filament manufacture, the FDM rice husk filament exhibited a lower melt strength and material surged at the die causing unevenness in the filament shape. These processing effects made the rice husk filament more difficult to manufacture.

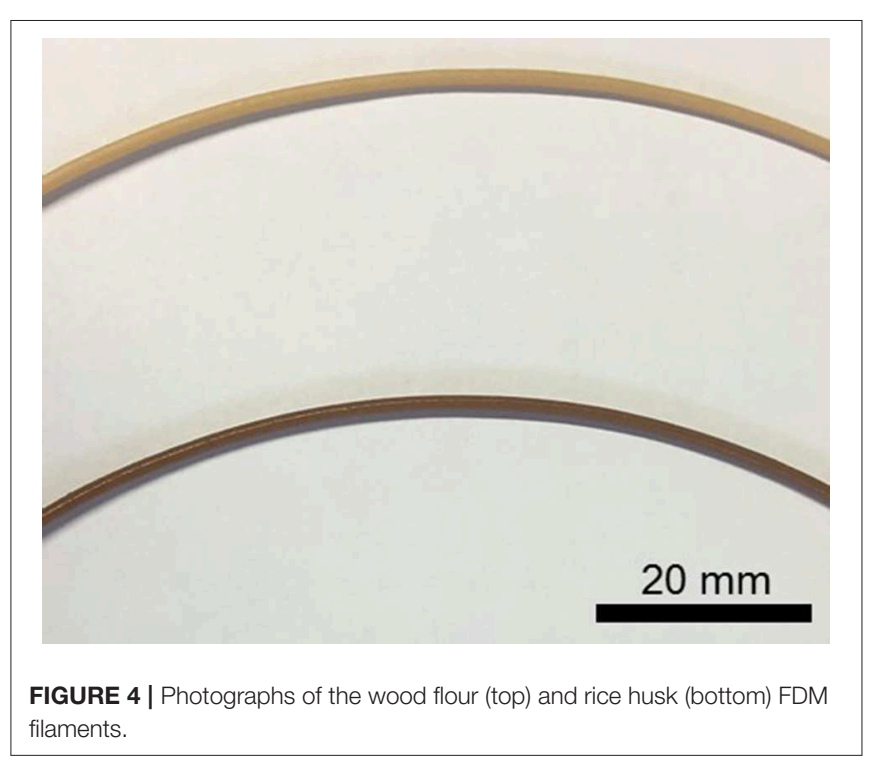

\section{Influence of the Biomass on the PLA}

In terms of rheology, the measurement of the complex viscosities of PLA and the PLA/biomass compounds as a function of frequency indicated that (a) the PLA-wood compound has a higher viscosity than neat PLA and that (b) both are exhibiting shear thinning behaviors (Figure 5). The findings are consistent with literature on biomass-filled polymers and the general effect of biomass in polymer melt (Li and Wolcott, 2004; Bettini et al., 2013; Gallos et al., 2017; Chun et al., 2018). Conversely, 
the rice compound was half the complex viscosity of neat PLA and indicated a poor reproducibility (Figure 5). It was hypothesized that the rice husk particles acted as a solid lubricant in the polymer matrix. However, the lack of reproducibility also suggested additional effects such as polymer hydrolysis of the backbone.

When comparing the PLA Mn and Mw of the biomass compounds, the GPC analysis indicated no significant difference between the two fillers (Table 4). More specifically, the GPC analysis gave a $\mathrm{Mw}$ and $\mathrm{Mn}$ of $98,020 \mathrm{~g} / \mathrm{mol}$ and $52,473 \mathrm{~g} / \mathrm{mol}$ for the neat PLA. After extrusion with biomass powders, significantly lower average molecular weights were recorded, i.e., $\mathrm{Mw}=$ $66,790 \mathrm{~g} / \mathrm{mol}$ and $\mathrm{Mn}=33,780 \mathrm{~g} / \mathrm{mol}$ for PLA-wood and $\mathrm{Mw}=$ $59,853 \mathrm{~g} / \mathrm{mol}$ and $\mathrm{Mn}=31,463$ for PLA-rice (Table 4, Figure 6). This finding is consistent with literature, as PLA is known to hydrolyse in the presence of moisture or acid groups in the biomass during extrusion (Le Guen et al., 2017; Thumm et al., 2018). This translated to an average molecular weight decrease of between 32 and 39\% for the PLA compounded with wood and rice husk powders. No significant difference was observed between fillers. The reduction was also observable

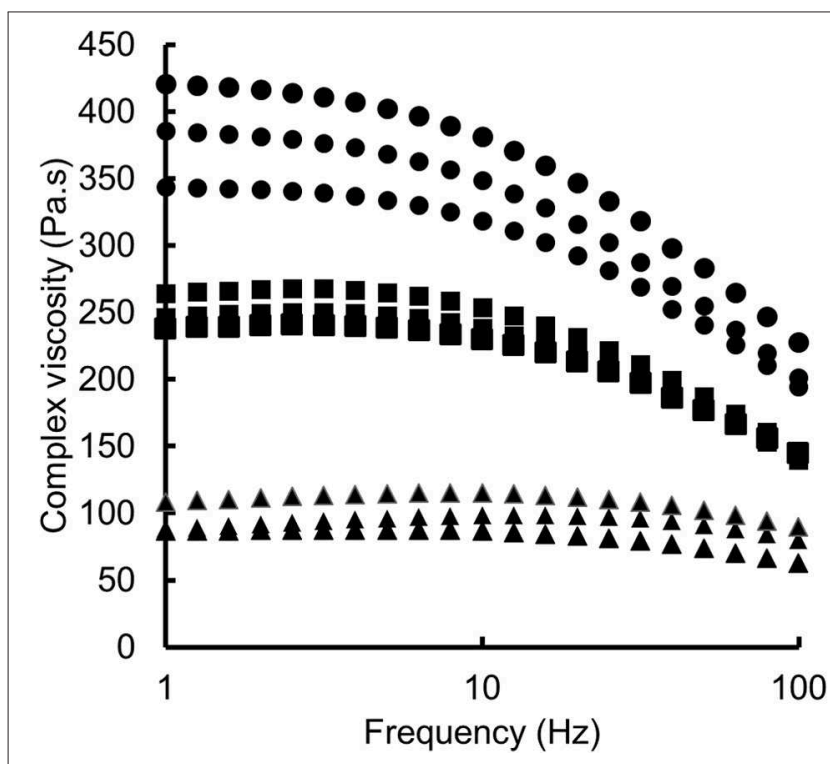

FIGURE 5 | Complex viscosity as a function of frequency for: PLA (Square), PLA-wood (Circle) and PLA-rice (Triangle). Triplicate measurements were carried out and all results are presented on the graph.

TABLE 4 | Molecular weight values and polydispersity indices of the PLA neat and compounded with biomasses.

\begin{tabular}{lcccccc}
\hline & $\begin{array}{c}\text { Mn } \\
(\mathbf{g} / \mathbf{m o l})\end{array}$ & $\begin{array}{c}\text { St. Dev. } \\
\mathbf{M n}(\mathbf{g} / \mathbf{m o l})\end{array}$ & $\begin{array}{c}\text { Mw } \\
(\mathbf{g} / \mathbf{m o l})\end{array}$ & $\begin{array}{c}\text { St. Dev. } \\
\mathbf{M w}(\mathbf{g} / \mathbf{m o l})\end{array}$ & $\begin{array}{c}\text { PDI } \\
(-)\end{array}$ & $\begin{array}{c}\text { St. Dev. } \\
\text { PDI (-) }\end{array}$ \\
\hline PLA & 52,473 & 5,245 & 98,020 & 6,294 & 1.9 & 0.24 \\
PLA-wood & 33,780 & 2,735 & 66,790 & 2,776 & 2.0 & 0.08 \\
PLA-rice & 31,463 & 3,526 & 59,853 & 5,963 & 1.9 & 0.03 \\
\hline
\end{tabular}

$n=3$. in the molecular weight distribution (MWD) profiles (Table 4). Similarly, no significant changes in the polydispersity indices (PDI) of pure PLA compared to PLA with biomasses were observed (Table 4).

When comparing the effect of the fillers onto PLA, the GPC analysis indicated that both resulted in similar level of PLA hydrolysis, hence, the difference rheological behavior could not be attributed to a difference in $\mathrm{Mn} / \mathrm{Mw}$.

\section{Mechanical Performances of the 3D Prints at $0^{\circ}$ and $90^{\circ}$}

The infill of the print direction was carried out at $0^{\circ}$ and $90^{\circ}$ of the length of the rectangular beam (Figure 7). The printing direction influenced the mechanical properties of all formulations, showing a decrease of flexural modulus and strength for the $90^{\circ}$ printed beams (Figure 8). The anisotropy induced difference in properties between the lengthwise and widthwise printing direction that ranged between 28 and $41 \%$ variation in flexural strength, 4 to $15 \%$ in strain and 27 to $33 \%$ in modulus. Similar mechanical properties results were reported for 3D printed PLA wood rectangular beam where the printing direction (i.e., $0^{\circ}$ and $90^{\circ}$ of the longitudinal axis of the beam) influenced the tensile stiffness and strength by 20 and $35 \%$, respectively (Le Duigou et al., 2016). They suggested that the mechanical properties differences between the lengthwise and widthwise printing directions were due to the lack of interlayer interactions.

No significant difference was found between the wood and the rice husk fillers in terms of mechanical property except for the flexural stiffness in the lengthwise direction where the PLAwood sample's modulus is $\sim 25 \%$ higher than the modulus of the PLA-rice samples. The decrease in strength compared to neat PLA and the lack of difference between the PLA-wood and PLA-rice compounds, indicated that the mechanical properties are effectively driven by the PLA inter-strands coalescence as observed by others (Le Duigou et al., 2016). This coalescence

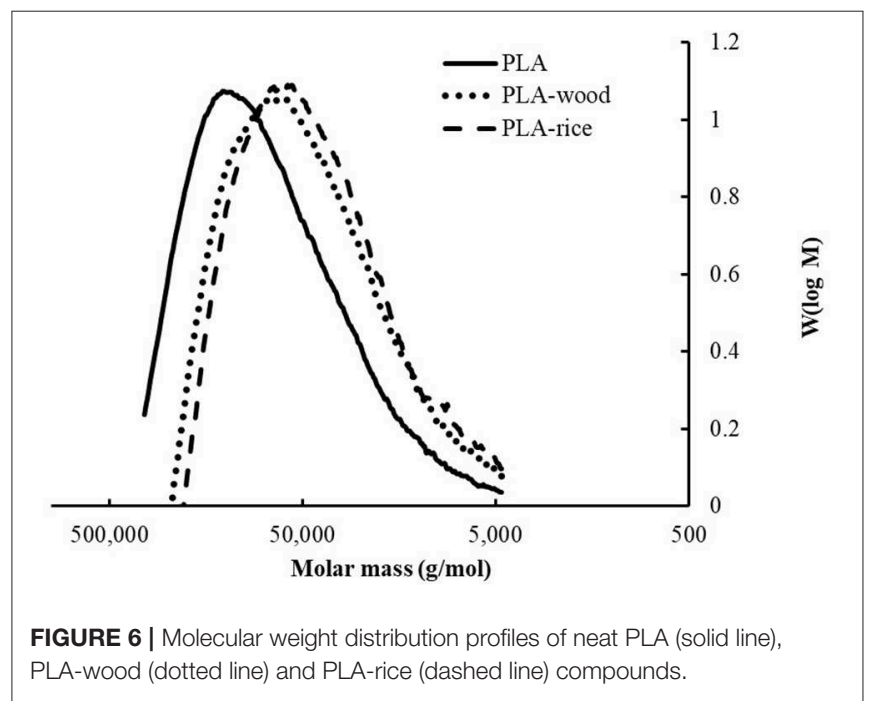




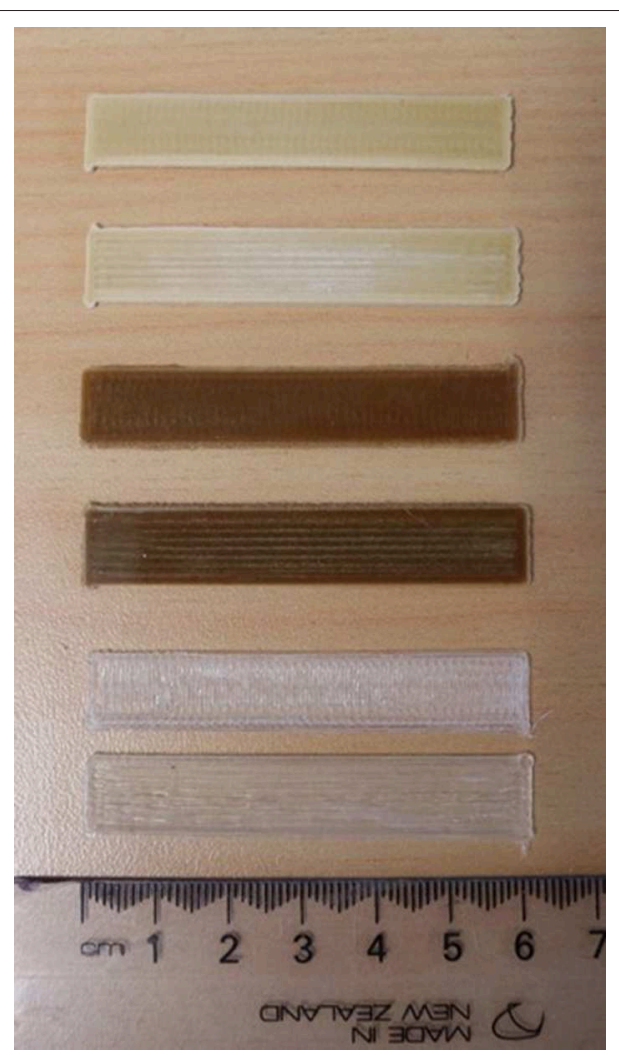

FIGURE 7 | Typical 3D printed rectangular beams for flexural testing. From bottom to top PLA $0^{\circ}, \mathrm{PLA} 90^{\circ}$, PLA-rice $0^{\circ}$, PLA-rice $90^{\circ}$, PLA-wood $0^{\circ}$ and PLA-wood 90.

is expected to decrease with the introduction of a solid filler that hinders the strand cohesion and creates weak points within the printed object. Singamenni et al., reported a gradual loss of inter-strand and inter-layer coalescence surface, measured by optical microscopy, with increasing amount of wood flour from 5 to 20 wt. $\%$ in polybutyrate-adipate-terephthalate-polymer matrix (PBAT) (Singamneni et al., 2018b). They attributed the decrease in flexural properties to the lower strands coalescence (98\% coalescence for $5 \mathrm{wt} . \%$ filler and $64 \%$ for $20 \mathrm{wt} . \%$ ). Their findings in terms of flexural strength are consistent with those presented in this study, where the addition of either filler decreases the flexural strength of the printed samples. However, their results relative to the flexural modulus differs. They reported a decrease in flexural modulus at $10 \mathrm{wt} . \%$ wood fraction whereas the present results indicate an increase of flexural modulus for the PLA-wood and decrease for the PLA-rice.

The difference was attributed to the polymer matrix as PBAT is more elastomeric than PLA but it raises the possibility of synergetic/competing effects between the type of filler and polymer, leading to different mechanical behavior of the $3 \mathrm{D}$ printed object. Similar findings were reported by Badouard et al. who compared the reinforcing ability of flax fibers in different biopolymer matrices (Badouard et al., 2019).

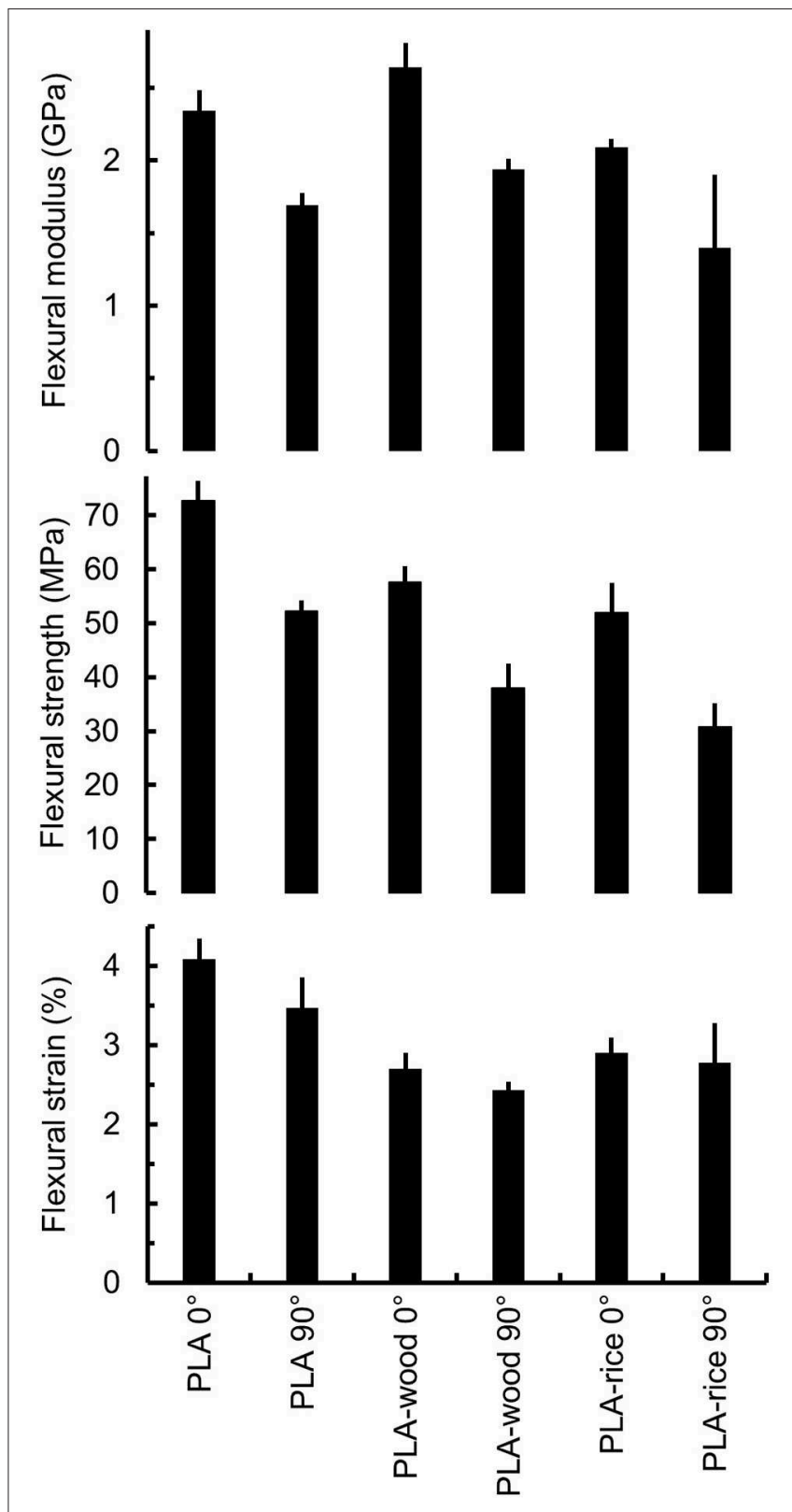

FIGURE 8 | Mechanical properties comparison of the 3D printed beams PLA, (Top) Flexural modulus (Middle) Flexural strength and (Bottom) Flexural strain (Error bars indicate the $\pm 95 \%$ confidence interval).

The dynamic thermo-mechanical behavior of the samples tested from 23 to $80^{\circ} \mathrm{C}$ indicated a single transition, typical of the glass transition temperature of PLA samples (Table 5).

The stiffness variation due to the printing direction anisotropy agreed with the quasi-mechanical tests for the neat PLA and filled samples. Storage modulus (E') values indicated a decrease of 28.7, 25.1, and $19.7 \%$ between $0^{\circ}$ and $90^{\circ}$ printing direction for respectively, the unfilled PLA, PLA-wood and PLA-rice samples, respectively (Table 5). The printing direction had no thermomechanical effect (e.g., Tg variation, thermal stress relaxation). 
TABLE 5 | Storage modulus values at 30 and $75^{\circ} \mathrm{C}$, and glass transition temperature (Tg) for PLA, PLA-wood, and PLA-rice samples printed at 0 and $90^{\circ}$ of the longitudinal direction.

\begin{tabular}{|c|c|c|c|c|c|c|}
\hline & $\begin{array}{c}\text { PLA } \\
0^{\circ}\end{array}$ & $\begin{array}{l}\text { PLA } \\
90^{\circ}\end{array}$ & $\begin{array}{c}\text { PLA-wood } \\
0^{\circ}\end{array}$ & $\begin{array}{c}\text { PLA-wood } \\
90^{\circ}\end{array}$ & $\begin{array}{c}\text { PLA-rice } \\
0^{\circ}\end{array}$ & $\begin{array}{c}\text { PLA-rice } \\
90^{\circ}\end{array}$ \\
\hline $\mathrm{E}^{\prime}$ at $30^{\circ} \mathrm{C}(\mathrm{GPa})$ & $2.66(0.22)$ & $1.90(0.15)$ & $2.31(0.07)$ & $1.73(0.16)$ & $2.50(0.15)$ & $2.01(0.43)$ \\
\hline $\operatorname{Tg}\left({ }^{\circ} \mathrm{C}\right)$ & $65.0(0.35)$ & $65.5(0.35)$ & $64.7(1.7)$ & $65.4(1.8)$ & $65.3(0.9)$ & $64.8(0.4)$ \\
\hline $\mathrm{E}^{\prime}$ at $75^{\circ} \mathrm{C}(\mathrm{MPa})$ & $5.6(0.5)$ & $3.9(1.6)$ & $12.8(2.7)$ & $7.8(1.1)$ & $8.6(1.7)$ & $13.4(1.2)$ \\
\hline
\end{tabular}

The number in brackets is the standard deviation for $n=3$.

However, the filler's contribution to the stiffness could be observed past the glass transition temperature where the storage modulus of the PLA-wood and PLA-rice samples was higher than the unfilled PLA samples. The retention of storage modulus indicated opposite trends between the PLA-wood samples $0^{\circ}$ and $90^{\circ}$, and the PLA-rice samples $0^{\circ}$ and $90^{\circ}$. Indeed, past the $\mathrm{Tg}$, the wood filled PLA samples displayed a $39 \%$ difference in favor of the longitudinal printing direction. Conversely, the ricehusk filled samples displayed an unexpected $56 \%$ difference in favor of the transversal printing direction. The former finding is explained by an alignment of wood particles in the printing direction caused by shear forces in the nozzle (Sydney Gladman et al., 2016). The latter finding is more difficult to explain. It was here tentatively attributed to the smaller size of the rice husk particles and their better distribution within the PLA. The rice husk particles are around 10 times smaller than the wood ones (Figure 2, Table 2). Considering the low aspect ratio of the rice husk particles, it is conceivable that no or little alignment for the rice husk particles occurred. The difference in behavior between the rice husk and the wood was tentatively attributed to the finer particles which created a more uniform and stiffening network. This characteristic was only observed in the widthwise direction as the predominant factor (i.e., the alignment of the polymer chains and fillers) was potentially not present to mask it.

\section{DISCUSSION}

Overall, the mechanical behavior of the $3 \mathrm{D}$ printed beams at room temperature was governed by the printing direction and the polymer physical properties rather than the type of fillers being used. However, when comparing the wood powder to the rice husk powder as a filler for $3 \mathrm{D}$ printing in PLA, particular observations were made on the interaction between the biomasses and PLA.

\section{Process Stability and Thinning Behavior}

Whilst both biomass fillers caused a reduction in the PLA molecular chain length, the extrusion process was more unstable during rice husk powder compounding. GPC analysis indicated that the degree of hydrolysis during processing was slightly higher for the rice husk powder than the wood powder, however the difference was not significant and could not alone justify the rheological differences. The complex viscosity analysis indicated a dramatic thinning effect of the rice husk particles on the PLA $(\sim$ 2.5 times lower at $1 \mathrm{~Hz}$ ). Thinning/plasticization additives is fairly common in polymer processing however, it is much less common in the case of solids in the 10 to 100's micron size range. Coppola et al. found that the addition of 3 and 5 vol.\%, powdered hemp shives in PLA reduced the complex viscosity of the compound compared to neat polymer (Coppola et al., 2018). This behavior was attributed to chemical degradation of the pectin contained in hemp shives. Conversely, Cipriano et al. reported the same effect on PLA caused by magnesium silicate particles (Cipriano et al., 2014). They attributed this lubricant effect to a physical interaction between the particles and the polymer chains.

In this study, both chemical and physical phenomena are valid. Rice husk is composed of 15.2 wt.\% amorphous silicate which contributes to its higher density compared to wood or other lignocellulosics (e.g., flax) and could contribute to the rheological thinning behavior as reported Cipriano et al. (2014). However, the concurrent presence of organic materials (e.g., carbohydrates) in the particles also points to a chemical triggered mechanism. The difference in chemical reactivity between wood and rice powders was attributed to the particles size and the ball milling. Ball milling of biomass is known to break down the carbohydrates which increases their reactivity (e.g., better enzymatic adsorption) (Vaidya et al., 2016; Gao et al., 2017). The possibility of reacting these carbohydrates at temperatures above $150^{\circ} \mathrm{C}$ in an extruder is highly probable leading to the faster production of oxidation products such as alcohols, acids or other volatile products (Formela et al., 2018).

\section{Reactive Extrusion of Lignocellulosic Biomass}

During compounding of biomass in PLA, hydrolysis of the polymer chains is known to occur (Le Guen et al., 2017; Thumm et al., 2018). A previous study comparing the mechanical behavior of PLA reinforced with protein-based filler and wood flour reported that under accelerated weathering, the proteinbased filler hydrolysed the PLA matrix at least twice as fast as a wood flour filler due to the amino-acids produced from protein hydrolysis (Le Guen et al., 2017). Rice husks contain more proteins than wood (Hamdan et al., 1997; Vadiveloo et al., 2009), however, the GPC analysis indicated comparable molecular weights for the PLA compounded with either wood or rice husk powders. This finding ruled out a potential difference solely based on acid hydrolysis of the PLA chains.

In the case of the rice husk compound, the darkening color could be attributed to two chemical reactions:

- Maillard reaction between the amino acids and the carbohydrates (e.g., xylan), that has been previously reported 
to occur during processing of the rice husks at $180^{\circ} \mathrm{C}$ (Vegas et al., 2008),

- Carbohydrate oxidation (i.e. caramelization) that is known to form volatile organic molecules (Jiang et al., 2008).

In both cases, the reactions release volatile compounds and water that can explain the instability of the rice husk compounding process and the plasticization of the PLA matrix. Whilst the oxidation reactions also occur with wood powder, the higher reactivity of the rice husk powder compared to the wood powder was attributed to the ball-milling pre-treatment.

\section{CONCLUSIONS}

Wood and rice husk powders were blended by twin-screw extrusion with PLA to be used for $3 \mathrm{D}$ printing applications. It was found that the mechanical properties of the $3 \mathrm{D}$ printed samples at room temperature were mainly driven by the properties of PLA and anisotropy was only influenced by the $3 \mathrm{D}$ printing directionality. In addition, the mechanical properties were lowered by the integration of either filler which was attributed to a lowering of inter-strand cohesion in the $3 \mathrm{D}$ printed samples. Past the glass transition temperature of the PLA, the fillers enabled the retention of stiffness measured by the storage modulus.

In terms of visual assessment and process stability however, differences were observed and attributed to chemical reactions triggered by the (a) silica content of rice husk and/or (b) chemical reactions including Maillard reaction and carbohydrate oxidations. These chemical reactions were potentially enhanced by a particle size difference (i.e., rice husk powder was smaller and denser than the wood powder) and triggered during the temperature and shearing conditions of the extrusion process. Little polymer research has been conducted on the potential of using reactive biomass filler particles based on mechano-chemistry (i.e., ball milling). These

\section{REFERENCES}

Badouard, C., Traon, F., Denoual, C., Mayer-Laigle, C., Paës, G., and Bourmaud, A. (2019). Exploring mechanical properties of fully compostable flax reinforced composite filaments for 3D printing applications. Indus. Crops Products 135, 246-250. doi: 10.1016/j.indcrop.2019. 04.049

Bettini, S. H. P., de Miranda Josefovich, M. P. P., Muñoz, P. A. R., Lotti, C., and Mattoso, L. H. C. (2013). Effect of lubricant on mechanical and rheological properties of compatibilized PP/sawdust composites. Carbohyd. Polymers 94, 800-806. doi: 10.1016/j.carbpol.2013.01.080

Bohren, C. F. and Huffman, D. R. (1983). Absorption and Scattering of Light by Small Particles. New York, NY: Wiley.

Bruker BioSpin (2018). TopSpin 4.0.5 NMR Guide [Computer Software]. Bruker BioSpin.

Chun, K. S., Husseinsyah, S., and Yeng, C. M. (2018). Torque rheological properties of agro-waste-based polypropylene composites: effect of filler content and green coupling agent. J. Vinyl Addit. Technol. 24, E30-E35. doi: 10.1002/vnl.21561

Chungsangunsit, T. (2009). Emission assessment of rice husk combustion for power production. Int. J. Mech. Aerospace, Indus. Mechatr. Manufact. Eng. 3. Available online at: https://pdfs.semanticscholar.org/7454/ b2f04cd9b56de336abe6ac904f100519f123.pdf unique findings indicate that biomass can trigger chemical reactions that change the polymer rheological behaviors during processing dramatically and reinforces the need for careful attention when matching a biopolymer matrix with a biomass filler.

The ball-milled rice husk powder's effect on thinning PLA, if controlled during the compounding process, is of major interest in the development of reactive sustainable plastic additives.

\section{DATA AVAILABILITY STATEMENT}

All datasets generated for this study are included in the manuscript/supplementary files.

\section{AUTHOR CONTRIBUTIONS}

M-JL and CM-L contributed to the design of the research. All authors contributed to its implementation and the analysis of the results as per field of expertise and wrote the manuscript.

\section{ACKNOWLEDGMENTS}

The authors thank the French GDR Symbiose, and the New Zealand Ministry of Business, Innovation, and Employment funding under High Value Manufacturing and Services (HVMS) Enabling Technologies investment contract C04X1205.

The authors are gratefully acknowledging the contribution of Mr. Ross Anderson and Mr. Bryce McQuillan for supplying and preparing the wood powder. The authors also want to acknowledge the team of the plant-based platform of the JRU IATE, particularly Charlène Fabre for preparing the rice husk powder. In addition, the authors want to express their gratitude to Dr. Mathias Sorieul, Mr. Armin Thumm, and Mr. Elouan Guillou for their helpful advice.

Cipriano, T. F. S., da Silva, A. L. N., da Silva, A. H. M., de Sousa, A. M. F., da Silva, G. M., and Rocha, M. G. (2014). Thermal, rheological and morphological properties of poly (Lactic Acid) (PLA) and talc composites. Polímeros 24:2. doi: 10.17265/2161-6221/2013.11.002

Coppola, B., Garofalo, E., Maio, L. D., Scarfato, P., and Incarnato, L. (2018). Investigation on the use of PLA/hemp composites for the fused deposition modelling (FDM) 3D printing. AIP Conference Proc. 1981:020086. doi: $10.1063 / 1.5045948$

Formela, K., Zedler, Ł., Hejna, A., and Tercjak, A. (2018). Reactive extrusion of bio-based polymer blends and composites - Current trends and future developments. Exp. Polymer Lett. 12, 24-57. doi: 10.3144/expresspolymlett.2018.4

Gallos, A., Paës, G., Allais, F., and Beaugrand, J. (2017). Lignocellulosic fibers: a critical review of the extrusion process for enhancement of the properties of natural fiber composites. RSC Adv. 7, 34638-34654. doi: 10.1039/C7RA0 $5240 \mathrm{E}$

Gao, C., Xiao, W., Ji, G., Zhang, Y., Cao, Y., and Han, L. (2017). Regularity and mechanism of wheat straw properties change in ball milling process at cellular scale. Bioresour. Technol. 241, 214-219. doi: 10.1016/j.biortech.2017. 04.115

Gibson, M. A., Mykulowycz, N. M., Shim, J., Fontana, R., Schmitt, P., Roberts, A., et al. (2018). 3D printing metals like thermoplastics: fused 
filament fabrication of metallic glasses. Mater. Today 21, 697-702. doi: 10.1016/j.mattod.2018.07.001

Giddel, M. R., and Jivan, A. P. (2007). "Waste to wealth, potential of rice husk in india a literature review," in International Conference on Cleaner Technologies and Environmental Management PEC, Pondicherry, 586-590.

Gil, A. M., and Neto, C. P. (1999). Solid-state NMR studies of wood and other lignocellulosic materials. Ann. Rep. NMR Spectrosc. 37, 75-117. doi: 10.1016/S0066-4103(08)60014-9

Graichen, F. H. M., Grigsby, W. J., Hill, S. J., Raymond, L. G., Sanglard, M., Smith, D. A., et al. (2017). Yes, we can make money out of lignin and other bio-based resources. Indus. Crops Products 106, 74-85. doi: 10.1016/j.indcrop.2016.10.036

Hamdan, H., Muhid, M. N. M., Endud, S., Listiorini, E., and Ramli, Z. (1997). 29Si MAS NMR, XRD and FESEM studies of rice husk silica for the synthesis of zeolites. J. Non-Crystalline Solids 211, 126-131. doi: 10.1016/S0022-3093(96)00611-4

Jiang, B., Liu, Y., Bhandari, B., and Zhou, W. (2008). Impact of caramelization on the glass transition temperature of several caramelized sugars. Part I: chemical analyses. J. Agric. Food Chem. 56, 5138-5147. doi: 10.1021/jf703791e

Juliano, B. O., Maniñgat, C. C., Pascual, G. C. (1987). Properties of fraction of rice hull. Phytochemistry 26, 3261-3263. doi: 10.1016/S0031-9422(00)82483-8

Kumar, A., Mohanta, K., Kumar, D., and Parkash, O. (2012). Properties and industrial applications of rice husk: a review. Int. J. Emerg. Technol. Adv. Eng. 2, 86-90.

Lammi, S., Le Moigne, N., Djenane, D., Gontard, N., and AngellierCoussy, H. (2018). Dry fractionation of olive pomace for the development of food packaging biocomposites. Indus. Crops Products 120, 250-261. doi: 10.1016/j.indcrop.2018.04.052

Le Duigou, A., Castro, M., Bevan, R., and Martin, N. (2016). 3D printing of wood fibre biocomposites: from mechanical to actuation functionality. Mater. Design 96, 106-114. doi: 10.1016/j.matdes.2016.02.018

Le Guen, M.-J., Thoury-Monbrun, V., Castellano Roldán, J. M., and Hill, S. J. (2017). Assessing the potential of farm dairy effluent as a filler in novel PLA biocomposites. J. Polymers Environ. 25, 419-426. doi: 10.1007/s10924-016-0824-1

Le Guen, M. J., and Newman, R. H. (2007). Pulped Phormium tenax leaf fibres as reinforcement for epoxy composites. Composites Part A. Appl. Sci. Manufact. 38, 2109-2115. doi: 10.1016/j.compositesa.2007.07.001

Li, T. Q., and Wolcott, M. P. (2004). Rheology of HDPE-wood composites. I. Steady state shear and extensional flow. Composites Part A. Appl. Sci. Manufact. 35, 303-311. doi: 10.1016/j.compositesa.2003.09.009

Liles, K. P., Greene, A. F., Danielson, M. K., Colley, N. D., Wellen, A., Fisher, J. M., Barnes, J. C. Photoredox-Based Actuation of an Artificial Molecular Muscle. Macromol. Rapid Commun. (2018) 39:1700781. doi: 10.1002/marc.201700781

Lv, H., Song, S., Sun, S., Ren, L., and Zhang, H. (2016). Enhanced properties of poly(lactic acid) with silica nanoparticles. Polymers Adv. Technol. 27, 1156-1163. doi: 10.1002/pat.3777

Malvern (2007). Sample Dispersion and Refractive Index Guide - Mastersizer 2000. Malvern.

Mirko, K., Sernek, M., and Kitek Kuzman, M. (2016). Use of wood powder and adhesive as a mixture for 3D printing. Eur. J. Wood Wood Products 74:123. doi: 10.1007/s00107-015-0987-9

Montalvo Navarrete, J. I., Hidalgo-Salazar, M. A., Escobar Nunez, E., and Rojas Arciniegas, A. J. (2018). Thermal and mechanical behavior of biocomposites using additive manufacturing. Int. J. Interact. Design Manufact. 12, 449-458. doi: 10.1007/s12008-017-0411-2

Muniyasamy, S. (2013). Biodegradability and compostability of lignocellulosic based composite Materials. J. Renew. Mater. 1:253.

Müssig, J. (2010). Industrial Applications of Natural Fibres: Structure, Properties and Technical Applications. John Wiley \& Sons, Ltd. doi: $10.1002 / 9780470660324$

Newman, R. H., Hemmingson, J. A., and Suckling, I. D. (1993). Carbon13 nuclear magnetic resonance studies of kraft pulping. Holzforschung, doi: 10.1515/hfsg.1993.47.3.234
Pode, R. (2016). Potential applications of rice husk ash waste from rice husk biomass power plant. Renew. Sustain. Energy Rev. 53, 1468-1485. doi: 10.1016/j.rser,.2015.09.051

Revelo, C. F., and Colorado, H. A. (2018). 3D printing of kaolinite clay ceramics using the Direct Ink Writing (DIW) technique. Ceram. Int. 44, 5673-5682. doi: 10.1016/j.ceramint.2017. 12.219

Shao, Y., Guizani, C., Grosseau, P., Chaussy, D., and Beneventi, D. (2018). Use of lignocellulosic materials and 3D printing for the development of structured monolithic carbon materials. Compos. Part B Eng. 149, 206-215. doi: 10.1016/j.compositesb.2018.05.035

Singamneni, S., Behera, M. P., Le Guen, M., and Zeidler, H. (2018a). Mechanism of bonding in seashell powder based ceramic composites used for binder-jet 3D printing. Bioceram. Dev. Appl. 108. Available online at: https://www. omicsonline.org/open-access/mechanism-of-bonding-in-seashell-powderbased-ceramic-compositesused-for-binderjet-3d-printing-2090-50251000108.pdf

Singamneni, S., Smith, D., LeGuen, M.-J., and Truong, D. (2018b). Extrusion $3 \mathrm{D}$ printing of polybutyrate-adipate-terephthalate-polymer composites in the pellet form. Polymers 10:922. doi: 10.3390/polym10080922

Sydney Gladman, A., Matsumoto, E. A., Nuzzo, R. G., Mahadevan, L., and Lewis, J. A. (2016). Biomimetic 4D printing. Nat. Mater. 15:413. doi: 10.1038/nmat4544

Tao, Y., Wang, H., Li, Z., Li, P., and Shi, S. Q. (2017). Development and application of wood flour-filled polylactic acid composite filament for 3D printing. Materials 10:339. doi: 10.3390/ma10040339

Thumm, A., Even, D., Gini, P.-Y., and Sorieul, M. (2018). Processing and properties of MDF fibre-reinforced biopolyesters with chain extender additives. Int. J. Polymer Sci. 2018:9. doi: 10.1155/2018/9601753

Ummah, H., Suriamihardja, D., Selintung, M., and Wahab, A. W. (2015). Analysis of chemical composition of rice husk used as absorber plates sea water into clean water. ARPN J. Eng. Appl. Sci. 10, 6046-6050.

Vadiveloo, J., Nurfariza, B., and Fadel, J. G. (2009). Nutritional improvement of rice husks. Anim. Feed Sci. Technol. 151, 299-305. doi: 10.1016/j.anifeedsci.2009.03.002

Vaidya, A. A., Donaldson, L. A., Newman, R. H., Suckling, I. D., Campion, S. H., Lloyd, J. A., et al. (2016). Micromorphological changes and mechanism associated with wet ball milling of Pinus radiata substrate and consequences for saccharification at low enzyme loading. Bioresour. Technol. 214, 132-137. doi: 10.1016/j.biortech.2016.04.084

Vegas, R., Kabel, M., Schols, H. A., Alonso, J. L., and Parajó, J. C. (2008). Hydrothermal processing of rice husks: effects of severity on product distribution. J. Chem. Technol. Biotechnol. 83, 965-972. doi: 10.1002/jctb.1896

Wang, Q., Sun, J., Yao, Q., Ji, C., Liu, J., and Zhu, Q. (2018). 3D printing with cellulose materials. Cellulose 25, 4275-4301. doi: 10.1007/s10570-018$1888-\mathrm{y}$

Yalçin, N., and Sevinç, V. (2001). Studies on silica obtained from rice husk. Ceram. Int. 27, 219-224. doi: 10.1016/S0272-8842(00)00068-7

Zeidler, H., Klemm, D., Böttger-Hiller, F., Fritsch, S., Le Guen, M. J., and Singamneni, S. (2018). 3D printing of biodegradable parts using renewable biobased materials. Proc. Manufact. 21, 117-124. doi: 10.1016/j.promfg.2018.02.101

Conflict of Interest: The authors declare that the research was conducted in the absence of any commercial or financial relationships that could be construed as a potential conflict of interest.

Copyright (๑) 2019 Le Guen, Hill, Smith, Theobald, Gaugler, Barakat and MayerLaigle. This is an open-access article distributed under the terms of the Creative Commons Attribution License (CC BY). The use, distribution or reproduction in other forums is permitted, provided the original author(s) and the copyright owner (s) are credited and that the original publication in this journal is cited, in accordance with accepted academic practice. No use, distribution or reproduction is permitted which does not comply with these terms. 